Article

\title{
Comparison of the Spatiotemporal Dynamics of Land Use Changes in Four Municipalities of China Based on Intensity Analysis
}

\author{
Siqin Tong ${ }^{1,2}$, Gang Bao ${ }^{1,3}$, Ah Rong ${ }^{1}$, Xiaojun Huang ${ }^{1,3}$, Yongbin Bao ${ }^{4}$ and Yuhai Bao ${ }^{1,3, *}$ \\ 1 College of Geographical Science, Inner Mongolia Normal University, Hohhot 010022, China; \\ tsq118446@163.com (S.T.); baogang@imnu.edu.cn (G.B.); 20180016@imnu.edu.cn (A.R.); \\ huangxiaojun@imnu.edu.cn (X.H.) \\ 2 Inner Mongolia Key Laboratory of Disaster and Ecological Security on the Mongolian Plateau, Inner \\ Mongolia Normal University, Hohhot 010022, China \\ 3 Inner Mongolia Key Laboratory of Remote Sensing and Geographic Information Systems, Inner Mongolia \\ Normal University, Hohhot 010022, China \\ 4 School of Environment, Northeast Normal University, Changchun 130024, China; baoyb924@nenu.edu.cn \\ * Correspondence: baoyuhai@imnu.edu.cn; Tel.: +86-133-1471-9512
}

Received: 18 March 2020; Accepted: 29 April 2020; Published: 2 May 2020

check for updates

\begin{abstract}
Land use/cover change (LUCC) is becoming one of the most important and interesting problems in the study of global environmental change. Identifying the spatiotemporal behavior and associated driving forces behind changes in land use is crucial for the regional sustainable utilization of land resources. In this study, we consider the four municipalities of China (Beijing, Tianjin, Shanghai, and Chongqing) and compare their spatiotemporal changes in land use from 1990 to 2015 by employing intensity analysis and barycenter migration models. We then discuss their driving forces. The results show that the largest reduction and increase variations were mainly concentrated in arable and construction land, respectively. The decrement and increment were the largest in Shanghai, followed by Beijing and Tianjin, and the least in Chongqing. Furthermore, the results of the barycenter migration model indicate that in addition to Beijing, the migration distances of construction land were longer than those of arable land in three other cities. Moreover, the application of intensity analysis revealed that the rate of land use change was also the greatest in Shanghai and the slowest in Chongqing during the whole study period, with all of their arable land being mainly transformed into construction land. The driving force analysis results suggest that the spatial and temporal patterns of land use change were the results of the socio-economic development, national policies, and major events. In other words, where there was a high rate of economic and population growth, the intensity of land use change was relatively large.
\end{abstract}

Keywords: land use/cover change; spatiotemporal changes; intensity analysis; driving forces; municipalities

\section{Introduction}

Land use/cover change (LUCC) has been recognized as an important part of global climate change and global environmental change research [1,2]. As the most direct signal of the impact of human activities on the Earth's surface and the natural ecosystem, it is the link between human socio-economic activities and ecological processes [3]. This process is closely related to the terrestrial surface material cycle and life process, affecting biosphere-atmosphere interactions, biodiversity, biogeochemical cycles, and the sustainable utilization of resources and the environment [4]. In the combined system of Population-Resources-Environment-Development (PRED), land resources are 
immovable and non-renewable, placing land characteristics in a central position [5]. With the growth of land development and utilization, the pattern, depth, and intensity of land use are constantly changing, which makes the associated ecological and social problems increasingly serious [6-8]. The International Geosphere-Biosphere Program (IGBP) and the International Human Dimensions Program on Global Environmental Change (IHDP) proposed a detailed LUCC research plan in 1995, which focused on land use/land cover dynamics research at regional and global scales [9]. The formulation of this plan established the direction for research into LUCC throughout the world. LUCC often reflect the relationships between humanity and nature [1]. LUCC is increasingly considered as a key and urgent research topic in the study of global environmental change [10]. It plays an important role in the study of global climate change, the carbon cycle, food security, biodiversity, etc. [11-13].

LUCC is affected by both natural and human activities, while displaying certain regularity [14]. The analysis of LUCC dynamics, the exploration of the associated driving factors, and the associated processes are helpful in understanding the ecosystem services and the changes of the earth system functions. It will also help to guide regional sustainable development [15]. At present, the study of LUCC mainly involves three aspects: (i) The study of land use evolution trends, including trends in the extent, magnitude, and spatial evolution of such changes [16,17], (ii) the analysis of the driving mechanisms behind LUCC $[18,19]$, and (iii) the development of relevant models based on the change processes to undertake simulations and to make predictions about LUCC [20-22]. The monitoring of dynamic land use processes is the basis of the analysis of the driving forces and the simulated predictions, which are of great significance for further research into LUCC [23,24].

The common methods of land use dynamics analysis include the transfer matrix method, mathematical statistics, the structural parameter method, and landscape pattern feature analysis [25]. The transfer matrix is a two-dimensional matrix and is obtained from the transformation relationship of land use status for different phases of the same area. It allows transformation information to be obtained about the location and change in areas of different land types at two time phases [26], and has been widely used in LUCC analysis [25-29]. In addition, there are two special methods that have become popular, namely the land use dynamic degree model and intensity analysis [30-36]. The land use dynamic degree model can be divided into single land use dynamic degree and comprehensive land use dynamic degree. These can quantitatively describe the change rate of land use and play an important role in comparing the regional differences in LUCC and in predicting future trends [30-34]. The concept of intensity analysis, first proposed in 2012 [35,36], is from the perspective of system theory, and is based on the transfer matrix of land use area from different periods. It calculates the conversion area and the changing intensity among land types at the interval level, category level, and transition level. Recently, many researchers have used intensity analysis for LUCC studies [35-39], where it has been shown that it is superior to the dynamic degree model, since the dynamic degree model can only calculate the loss intensity, while intensity analysis can calculate the contribution rate of each category to the total change, the loss and gain of different categories, their intensities for each period, and the conversion extent and intensity between each category [40].

The aggravation of human economic activities and the extensive urbanization processes currently underway largely cause the change of urban land use patterns and even led to land use patterns that are contrary to natural trends [41]. These directly or indirectly change the structure and function of the landscape ecosystem, and have a profound impact on regional biodiversity and ecological processes [42,43]. As the most obvious change of the natural landscape, the process of urban land use change has become an important issue for scientists, planners, and decision makers. Land use changes in the four special municipalities of China, namely Beijing, Tianjin, Shanghai, and Chongqing, have received considerable attention. For example, it has been found that between 1999 and 2017, the built-up area increased and arable and forest land decreased in Beijing [44], where more than $10 \%$ of the cropland areas were transformed into built-up areas [45]. This is the main characteristic of land use change in Shanghai, where the expansion of the urban construction land occupied vast areas of farmland and forest land [46]. The proportion of unused land and cultivated land decreased 
rapidly, and the proportion of forest land and residential areas increased at a high rate in Chongqing between 1997 and 2009 [47]. However, there has not been a systematic comparative analysis for LUCC considering these four areas together.

Therefore, the purpose of this study is using the intensity analysis method to study (a) the land use change over time and space in these four municipalities; (b) the comparison of the speed of land use change (fast or slow); (c) the transformation between each land use category and whether they are active or not; and (d) the discussion of the driving forces behind the associated land use changes. This will provide a reference for developing land use plans, land protection policies, optimizing land utilization structures, and coordinating social and economic development and preserving the ecological environment.

\section{Materials and Methods}

\subsection{Study Area}

Municipalities are the most important provincial administrative regions in many countries. They usually play an important role in the political, economic, and cultural life of the country. Becoming a municipality in China requires certain conditions to be met, such as: (a) It has obvious advantages in location, economy, and politics, and its economic volume is higher than other major cities in China, (b) the population is not less than 2 million, (c) it has a certain economic basis, at least to reach the level of self-sufficiency, which is convenient for future government regulation and control, etc. At present, China has four municipalities (i.e., Beijing, Shanghai, Tianjin, and Chongqing); Chongqing became a municipality in 1949, and the other three cities were already municipalities in 1949.

As the capital of China, Beijing is the center of political, cultural, and international exchange in China, along with having substantial international influence. It has a population of about 21.8 million and had a GDP of 3631 billion USD in 2015 . It is located from around $39^{\circ} 28^{\prime}$ to $41^{\circ} 05^{\prime} \mathrm{N}$, and $115^{\circ} 25^{\prime}$ to $117^{\circ} 30^{\prime} \mathrm{E}$, with a total area of $16,800 \mathrm{~km}^{2}$, of which $61.4 \%$ is mountainous, being generally high in the northwest and low in the southeast (Figure 1). Tianjin is adjacent to Beijing, and it is the economic center of the Bohai Rim region, with a total area of $11,917.26 \mathrm{~km}^{2}$, a population of 13 million, and a GDP of 2530 billion USD in 2015. Shanghai is the economic, financial, trade, and shipping center of China. Located around $120^{\circ} 51^{\prime}$ to $122^{\circ} 12^{\prime} \mathrm{E}$ and $30^{\circ} 40$ to $31^{\circ} 53^{\prime} \mathrm{N}$, with a total area of $6341 \mathrm{~km}^{2}$, it is situated in the middle of the coastline of China's Yangtze River Estuary, and is China's largest foreign trade port and largest industrial base. Its GDP reached 3986 billion USD in 2015. Chongqing is located at the intersection of the Yangtze River and Jialing River, and is an important industrial and commercial city in southwest China, being located at the junction of economic development in central and western China, between $105^{\circ} 11^{\prime}$ and $110^{\circ} 11^{\prime} \mathrm{E}$ and $28^{\circ} 10^{\prime}$ to $32^{\circ} 13^{\prime} \mathrm{N}$. Its terrain is dominated by low mountains and hills, with a total area of $82,400 \mathrm{~km}^{2}$. Among the four municipalities, it has the largest population and the lowest GDP, with a population of about 30.5 million and a GDP of 2500 billion USD in 2015. 


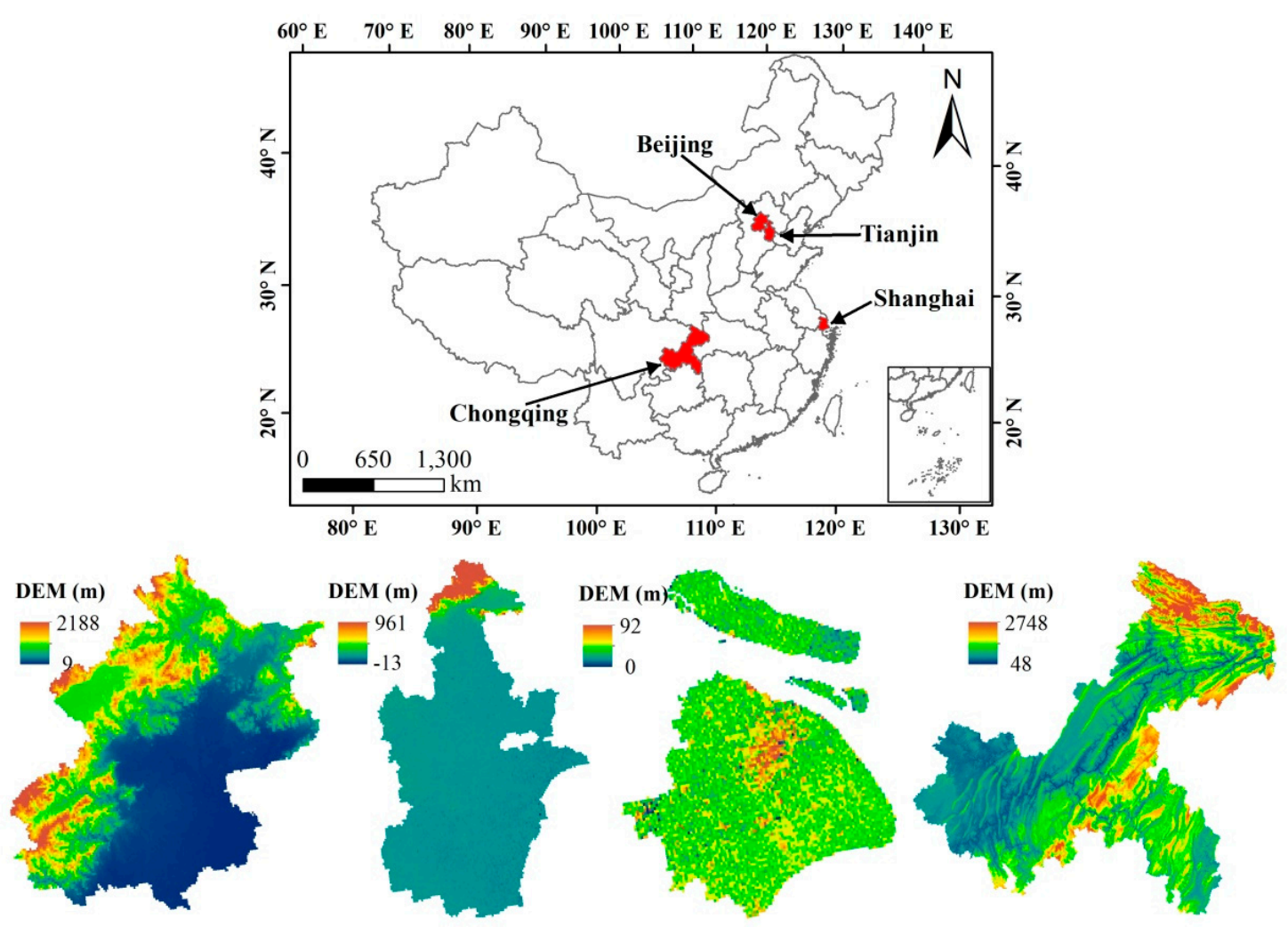

Figure 1. The locations and topographies of the study areas-Beijing, Tianjin, Shanghai, and Chongqing.

\subsection{Data Sources and Methodology}

\subsubsection{Data Source}

The LUCC data for 1990, 1995, 2000, 2005, 2010, and 2015 were provided by the Data Center for Resources and Environmental Sciences, Chinese Academy of Sciences (RESDC) (http://www.resdc.cn), with a $1 \mathrm{~km}$ spatial resolution. The primary sources of the LUCC dataset in the RESDC were Landsat Thematic Mapper/ Enhanced Thematic Mapper (TM/ETM) images. The land use data were obtained by image processing, human-machine interaction interpretation, dynamic extraction, and field investigation verification.

The dataset starts with the national land use database with a scale of 1:100,000, using the fast extraction method of human-computer interaction based on Landsat images with land interpretation symbol, and then updates to the database every five years. (a) For the spatial resolution, taking the $1 \mathrm{~km}$ raster background data and interpreted land use vector data as the basis of land use dynamic division, the spatial accuracy can be guaranteed on the basis of eliminating the scale effect of spatial data. By the vector and raster overlaying, cutting can be used to obtain the land use type distribution and area in each raster grid [48]. (b) In the specific operation for the update of the database, for example, by comparing the images of 2005 and 2010, based on the land use classification data of 2005, the dynamic information coding of land use change is determined and plotted, which reflects the land use types of the changed land in 2005 and 2010 at the same time. (c) In order to ensure the interpretation quality and consistency of the acquired data, a unified quality check and data integration are carried out for each dataset. A large number of field survey records and photographs are obtained in the early stage of research and development of each dataset, mostly autumn in the north area and spring in the south area. Then, the accuracy of field survey and field records is verified by random sampling according to the proportion of $10 \%$ of the counties. The comprehensive evaluation accuracy of the major class of land use type is $94.3 \%$, and more than $91.2 \%$ for the secondary subclasses of land use types $[48,49]$. The flowchart of the data acquisition process is shown in Figure 2. 


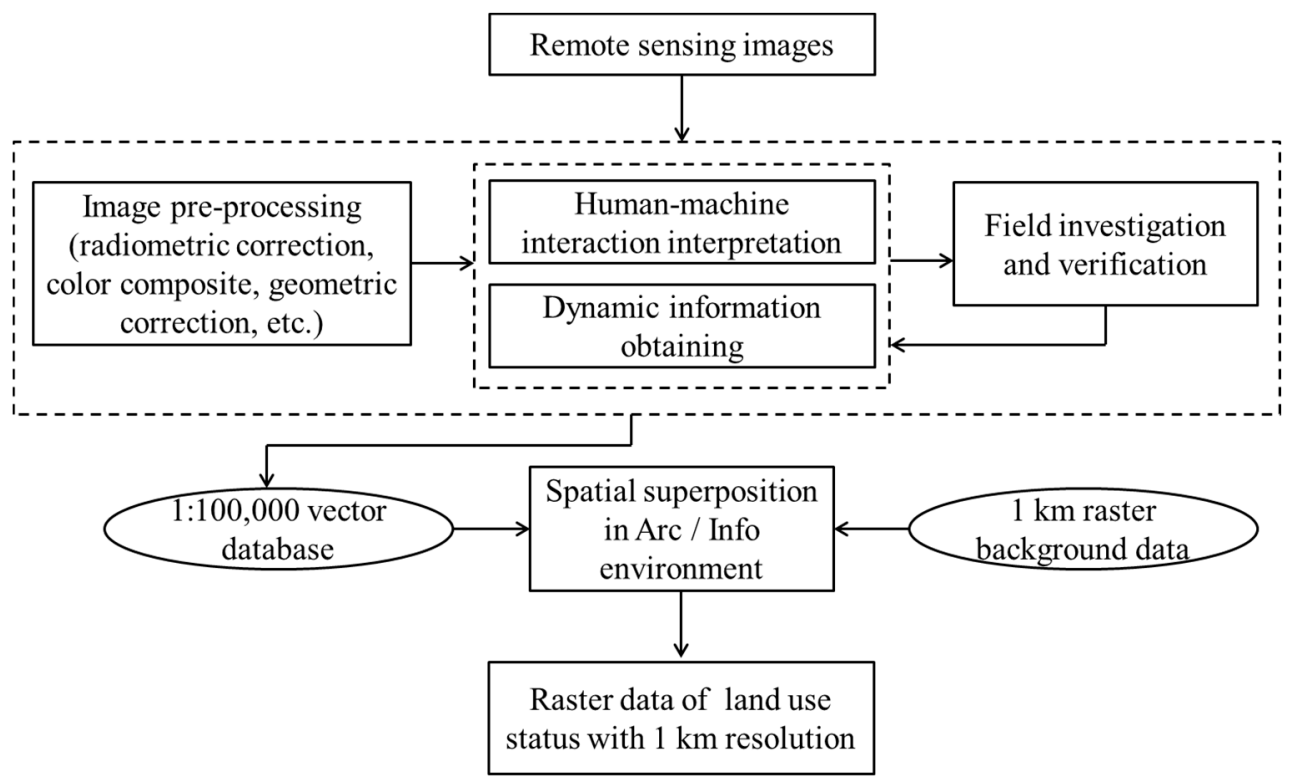

Figure 2. The flowchart of generation of the land use raster data with $1 \mathrm{~km}$ resolution.

The original dataset contains 6 major classes and 25 secondary subclasses. This dataset provides convenient and effective data support for the study of land use changes and is widely used by scholars in China [48,49]. In this study, the land use types are reclassified into arable land, forest land, grassland, water, construction land, and unused land, so as to study and analyze the distribution characteristics, spatiotemporal evolution, and driving forces of land use change and evolution. The socio-economic data were downloaded from the National Bureau of Statistics (http://www.stats.gov.cn/).

\subsubsection{Barycenter Migration Model}

The barycenter migration model of land use can effectively describe the spatial and temporal evolution of land use types [50]. By understanding the distribution centers of various land use types in each study period, we can find the spatial change of land use. The barycenter coordinates are generally represented by longitude and latitude, and are given by [51]:

$$
\begin{gathered}
X_{t}=\sum_{i=1}^{m}\left(C_{t i} X_{i}\right) / \sum_{i=1}^{m} C_{t i} \\
Y_{t}=\sum_{i=1}^{m}\left(C_{t i} Y_{i}\right) / \sum_{i=1}^{m} C_{t i}
\end{gathered}
$$

where $X_{t}$ and $Y_{t}$ are the longtitude and latitude of the center of a certain land use type in the $t$-th year, $C_{t i}, X_{i}$, and $Y_{i}$ are the area, longitude, and latitude values, respectively, of the $i$-th patch in the $t$-th year, and $m$ is the total number of patches of a certain land use type.

The measurement of the interannual distance of the movement of a land use type's barycenter is calculated as follows [52]:

$$
D_{t^{\prime}-t}=C \cdot\left[\left(X_{t^{\prime}}-X_{t}\right)^{2}+\left(Y_{t^{\prime}}-Y_{t}\right)^{2}\right]^{\frac{1}{2}}
$$

where $D$ represents the barycenter migration distance of land use from time $t$ to $t^{\prime},\left(X_{t^{\prime}}, Y_{t^{\prime}}\right)$ and $\left(X_{t}, Y_{t}\right)$ are the geographical coordinates of the barycenter at these times, and $C$ is a constant equal to 111.111 and is the coefficient of converting the geographical coordinate unit into the plane distance $(\mathrm{km})$. 


\subsubsection{Intensity Analysis}

Intensity analysis is a quantitative method used to analyze maps of land categories from several points in time for a single site by considering cross-tabulation matrices, where one matrix summarizes the change at each time interval. It is called "Intensity Analysis" because the method accounts for the intensity of land transitions while answering the following three interrelated questions by examining the degree to which changes are non-uniform at three levels: Interval, category, and transition, to answer the following three questions, respectively: (1) Over what time intervals is the annual rate of overall change relatively slow versus fast? (2) Given the answer to question 1, which land categories are relatively dormant versus active at a given time? (3) Given the answers to questions 1 and 2, which transitions are intensively avoided versus targeted by a given land category over a given time interval?

The interval intensity analysis computes the total change size and rate over each time interval, and compares the change rate with a uniform rate of change [35-39]. This is calculated by Equations (4) and (5):

$$
\mathrm{U}=\frac{\sum_{t=1}^{T-1}\left\{\sum_{j=1}^{J}\left[\left(\sum_{i=1}^{J} C_{t i j}\right)-C_{t j j}\right]\right\} /\left[\sum_{j=1}^{J} \sum_{i=1}^{J} C_{t i j}\right]}{Y_{T}-Y_{1}} \times 100 \%
$$

where $\mathrm{U}$ is the value of a uniform line for time intensity analysis, $C_{t i j}$ represents the areas that transition from category $i$ at time $Y_{t}$ to category $j$ at time $Y_{t+1}$ (the same below), $J$ is the number of land use categories (the same below), $T$ is the number of time points, $t$ is the index for a time point, which ranges from 1 to $T-1, Y_{t}$ is the year at time point $t$ (the same below), $i$ is the index for a land use category at an initial time, and $j$ is the index for a land use category at a final time. This is continued by considering the following:

$$
S_{t}=\frac{\left\{\sum_{j=1}^{J}\left[\left(\sum_{i=1}^{J} C_{t i j}\right)-C_{t j j}\right]\right\} /\left[\sum_{j=1}^{J} \sum_{i=1}^{J} C_{t i j}\right]}{Y_{t+1}-Y_{t}} \times 100 \%
$$

where $S_{t}$ is the annual intensity of change for time interval $\left[Y_{t}, Y_{t+1}\right]$.

The category level of intensity analysis examines how the intensity of change varies among the land use categories. It computes the intensity of annual gross gains and losses for each category, and then compares them with a uniform intensity. Calculated by Equations (6) and (7), this is expressed as:

$$
G_{t j}=\frac{\left[\left(\sum_{i=1}^{J} C_{t i j}\right)-C_{t i j}\right] /\left(Y_{t+1}-Y_{t}\right)}{\sum_{i=1}^{J} C_{t i j}} \times 100 \%
$$

where $G_{t j}$ is the annual intensity of gross gain of category $j$ for time interval $\left[Y_{t}, Y_{t+1}\right]$, and

$$
L_{t i}=\frac{\left[\left(\sum_{j=1}^{J} C_{t i j}\right)-C_{t i i}\right] /\left(Y_{t+1}-Y_{t}\right)}{\sum_{j=1}^{J} C_{t i j}} \times 100 \%
$$

where $L_{t i}$ is the annual intensity of gross loss of category i for time interval $\left[Y_{t}, Y_{t+1}\right]$.

The transition level of intensity analysis analyzes the intensity of any given transition from one category to another and examines it for a particular time interval when conversion is strong. This is calculated by Equations (8)-(10):

$$
W_{t n}=\frac{\left[\left(\sum_{i=1}^{J} C_{t i n}\right)-C_{t n n}\right] /\left(Y_{t+1}-Y_{t}\right)}{\sum_{j=1}^{J}\left[\left(\sum_{i=1}^{J} C_{t i j}\right)-C_{t n j}\right]} \times 100 \%
$$


where $W_{t n}$ is the value of uniform intensity of transition to category $n$ from non-n categories at time $Y_{t}$ during the time interval $\left[Y_{t}, Y_{t+1}\right]$, and $n$ is the land use category that other categories have transitioned into $(i \neq n)$. In addition,

$$
R_{t i n}=\frac{C_{t i n} /\left(Y_{t+1}-Y_{t}\right)}{\sum_{j=1}^{J} C_{t i j}} \times 100 \%
$$

where $R_{\text {tin }}$ is the annual intensity of transition from category $i$ to category $n$ during time interval $\left[Y_{t}, Y_{t+1}\right]$, and

$$
V_{t m}=\frac{\left[\left(\sum_{j=1}^{J} C_{t m j}\right)-C_{t m m}\right] /\left(Y_{t+1}-Y_{t}\right)}{\sum_{i=1}^{J}\left[\left(\sum_{j=1}^{J} C_{t i j}\right)-C_{t i m}\right]} \times 100 \%
$$

where $V_{t m}$ is the value of uniform intensity of transition from category $m$ to all non-m categories at time $Y_{t+1}$ during time interval $\left[Y_{t}, Y_{t+1}\right]$, and $m$ is the land use categories that transitioned into other categories. Finally,

$$
Q_{t m j}=\frac{C_{t m j} /\left(Y_{t+1}-Y_{t}\right)}{\sum_{i=1}^{J} C_{t i j}} \times 100 \%
$$

where $Q_{t m j}$ is the annual intensity of transition from category $m$ to category $j$ during time interval $\left[Y_{t}, Y_{t+1}\right](j \neq m)$.

\section{Results}

\subsection{Land Use Area Change in the Four Municipalities}

From the percentage of the area of the different land use types for the period 1990-2015 in the study areas, we can see that forest land holds the largest proportion in Beijing, while arable land was the largest in the other three municipalities (Figure 3). For Tianjin and Shanghai, since they have famous ports, the land use types with the next largest proportions were water and construction land.
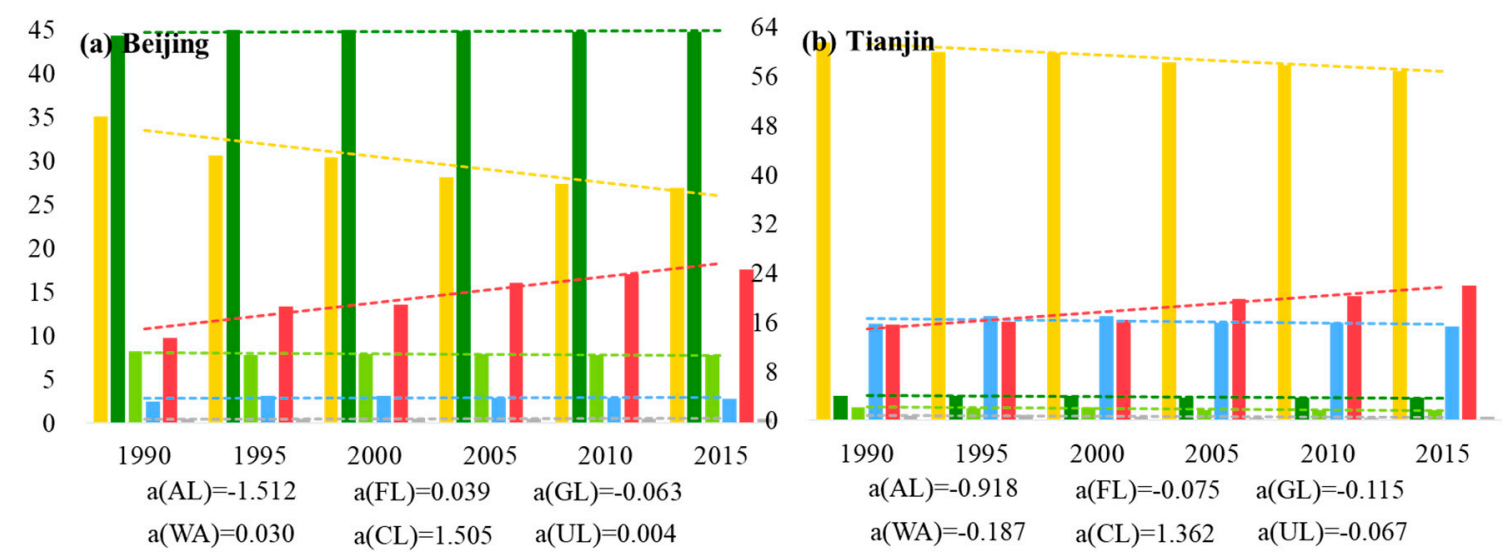

Figure 3. Cont. 


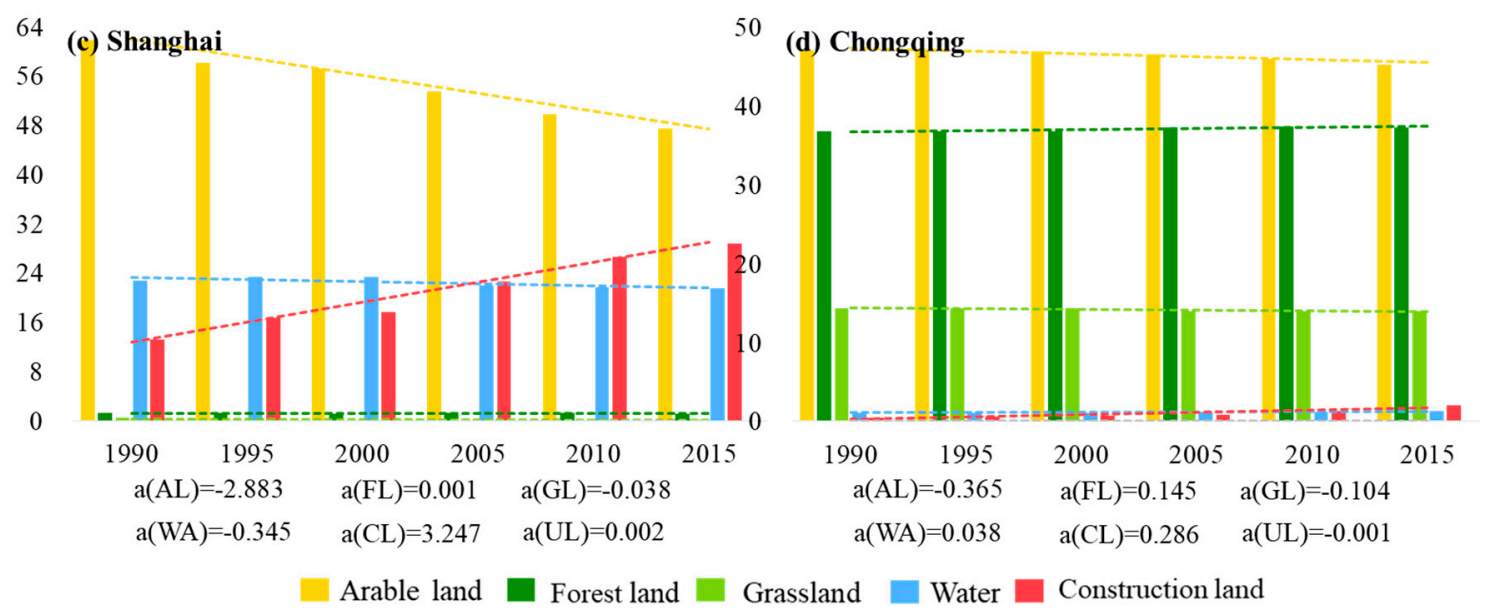

Figure 3. Area percentage change of land use types in (a) Beijing, (b) Tianjin, (c) Shanghai and (d) Chongqing. Dashed lines indicate the slopes of changes and are denoted as "a". $\mathrm{AL}=$ arable land, $\mathrm{FL}=$ forest land, $\mathrm{GL}=\mathrm{Grassland}, \mathrm{WA}=$ water, $\mathrm{CL}=$ construction land, $\mathrm{UL}=$ unused land.

In Beijing, the area of arable land decreased by about $10 \%$, while construction land increased from $9.74 \%$ to $17.59 \%$, leading to linear trends of $-1.512 \% / y$ and $1.505 \% / y$, from 1990 to 2015, respectively (Figure 3a). Except for the construction land, which has an increasing tendency $(a=1.362)$, the extents of the other types of land are decreasing in Tianjin city, with the arable land showing the greatest decrease (Figure 3b). For Shanghai, the arable land showed a significant decrease with a rate of $-2.883 \% / \mathrm{yr}$, the area decreasing from $62 \%$ to $47.67 \%$, while the construction land significantly increased $(a=3.247)$ (Figure 3c). Because of Chongqing's vast territory and its topography, the areas of arable land, forest land, and grassland account for more than $95 \%$ of the total area of the municipality. The rate of land use change in Chongqing was lower than for the other three municipalities, although there was still a characteristic decrease in arable land and an increase in construction land (Figure 3d).

\subsection{Spatial Distributions of Land Use Change in the Four Municipalities}

It can be seen from Figure 4 that construction land was mainly distributed in the southeast of Beijing, and the arable land was also mainly distributed in the southeast and surrounded the urban area in a semicircular ring, with sporadic distribution in the northwest. Moreover, it was obvious that construction land expanded outwards and occupied arable land during 1990-2015. The forest land was distributed in the west and north of Beijing, and because of the "Sandification Control Program for Beijing and Tianjin Vicinity" and the "Croplands to Forests or Grassland Program", the area of forest land increased after 2000. The forests and grasslands are distributed in the north of Tianjin, with water and construction land mainly in the middle and southern parts. The areas of arable land, water, and construction land were larger in Shanghai, with water mainly distributed in the north of Shanghai and the construction land in the middle. With increasing urbanization, it was clear that the construction land expanded and arable land decreased over the study period in Shanghai. Because of the mountainous areas, the eastern part of Chongqing was mainly forests and grasslands, the central and western parts were arable land, and the construction land was mainly concentrated in the west. 

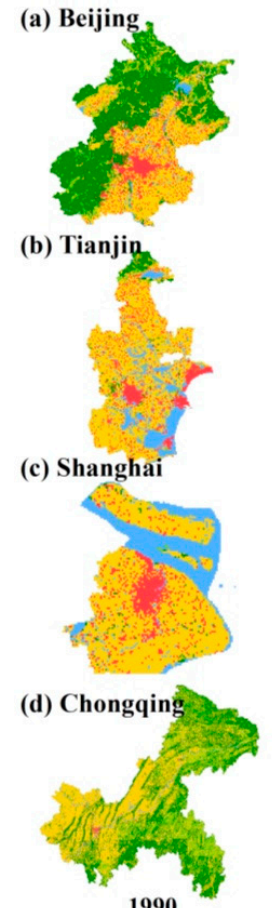

1990
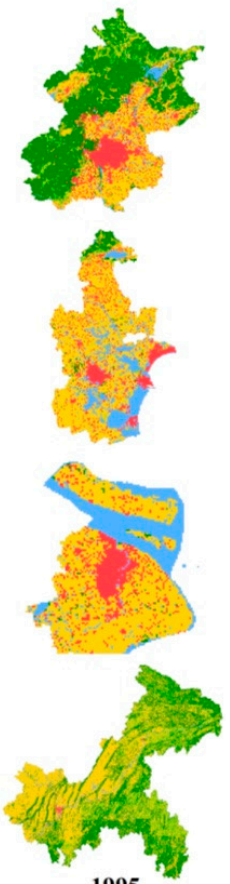

1995
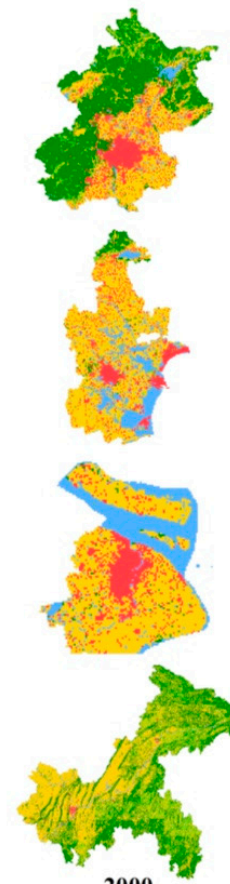

2000
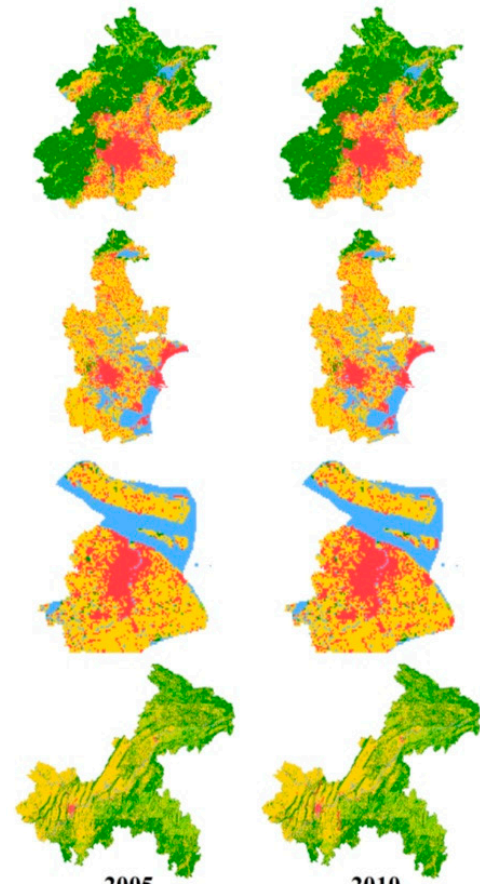

2005

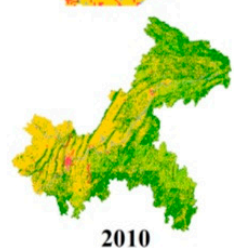

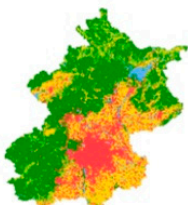
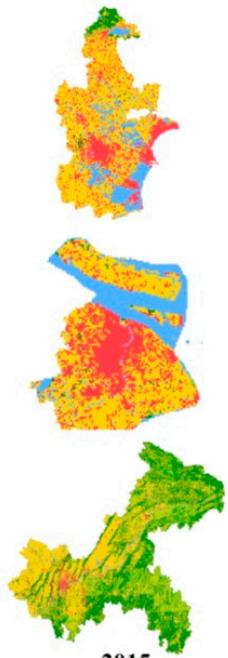

2015

Figure 4. Land use maps of (a) Beijing, (b) Tianjin, (c) Shanghai and (d) Chongqing from 1990 to 2015.

Figure 5 shows the spatial migration trajectories of arable and construction land in the four municipalities. The moving track of the barycenter of Beijing's arable land over each time segment was generally "east-north-south-north-east". In 1990, the barycenter coordinates of arable land were $116.506^{\circ} \mathrm{E}, 40.042^{\circ} \mathrm{N}$, which then moved to $116.524^{\circ} \mathrm{E}, 40.052^{\circ} \mathrm{N}$ by 2015 . During the period between 1990 and 2015, the barycenter of arable land in Beijing moved towards the northeast over a distance of $2.29 \mathrm{~km}$. The migration of the barycenter of the construction land was found to be "west-south-east-southwest", and over the study period, it generally moved to the southeast for a distance of $0.65 \mathrm{~km}$. The barycenter of arable and construction land in Tianjin moved towards the northeast and southwest with distances of $1.13 \mathrm{~km}$ and $4.39 \mathrm{~km}$, respectively. There is a U-shaped pattern of the arable barycenter migration in Shanghai; specifically, from 1990 to 2000, it moved southwards and then to the east from 2000 to 2005, and then towards the north from 2005 to 2015. In general, the barycenter of arable land in Shanghai moved to the northeast and its migration distance was $1.01 \mathrm{~km}$. Construction land moved $2.76 \mathrm{~km}$ towards the southeast from 1990 to 2015 . From Figure 4, it can be seen that in Chongqing, there were two stages for the migration of the barycenter of arable land, that is, it first moved to the southwest between 1990 to 2005, and then to the northeast from 2005 to 2015; hence, between 1990 to 2015, it moved to the south for a distance of $0.26 \mathrm{~km}$, while the barycenter of the construction land moved toward the northeast by $12.72 \mathrm{~km}$. 

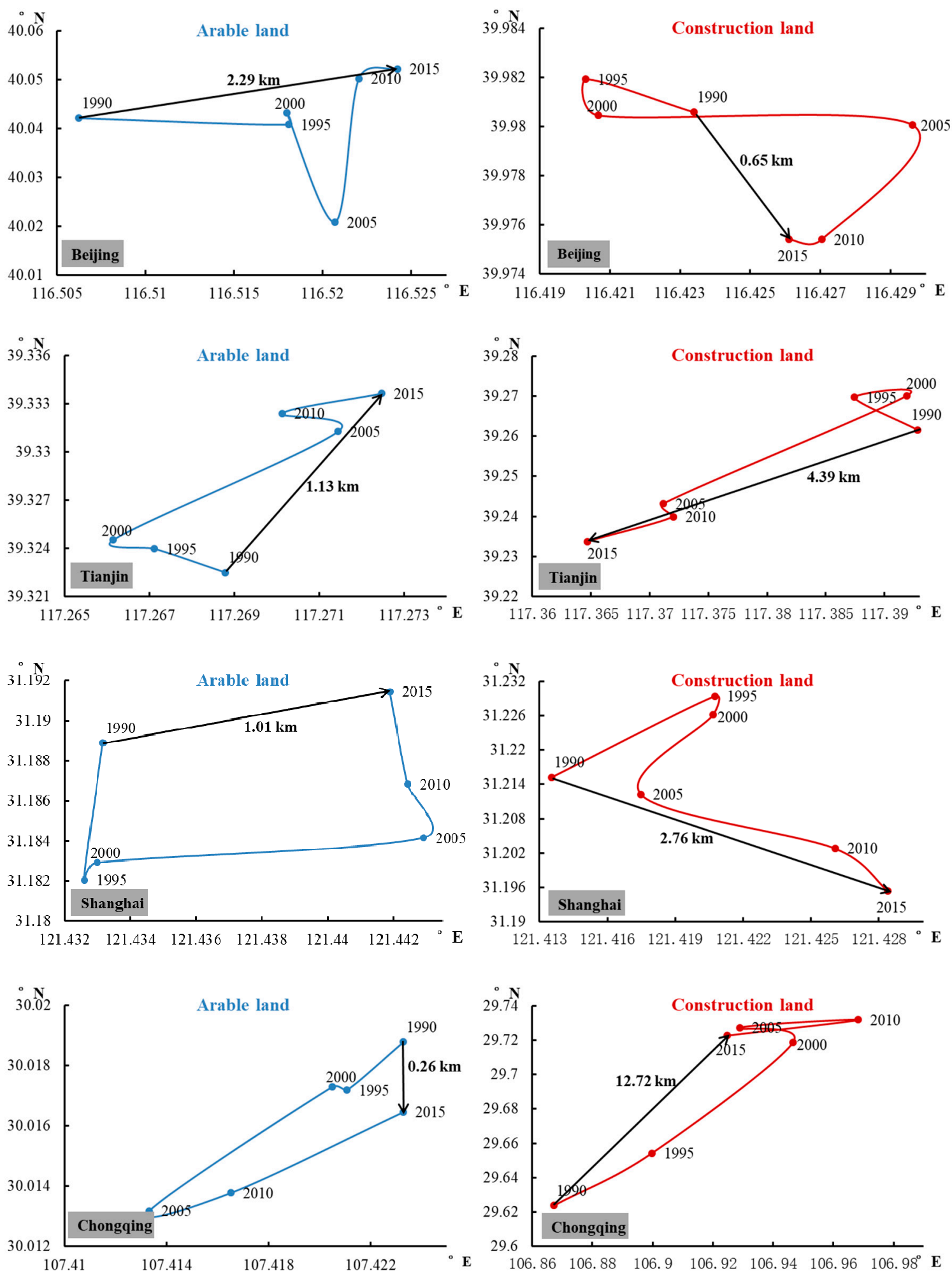

Figure 5. Migrations of arable and construction land barycenters in the four municipalities from 1990 to 2015. The black arrow lines indicate the moving distances.

\subsection{Intensity Analysis Results of Land Use Change in Four Municipalities}

The results of the interval intensity analysis are shown in Figure 6. It can be seen that the uniform intensities of LUCC in Beijing, Tianjin, Shanghai, and Chongqing were $0.49 \%, 0.50 \%, 0.76 \%$, and $0.15 \%$, 
respectively, during the study period. Land use change was most rapid in Shanghai, followed by Beijing and Tianjin, with Chongqing being the slowest.
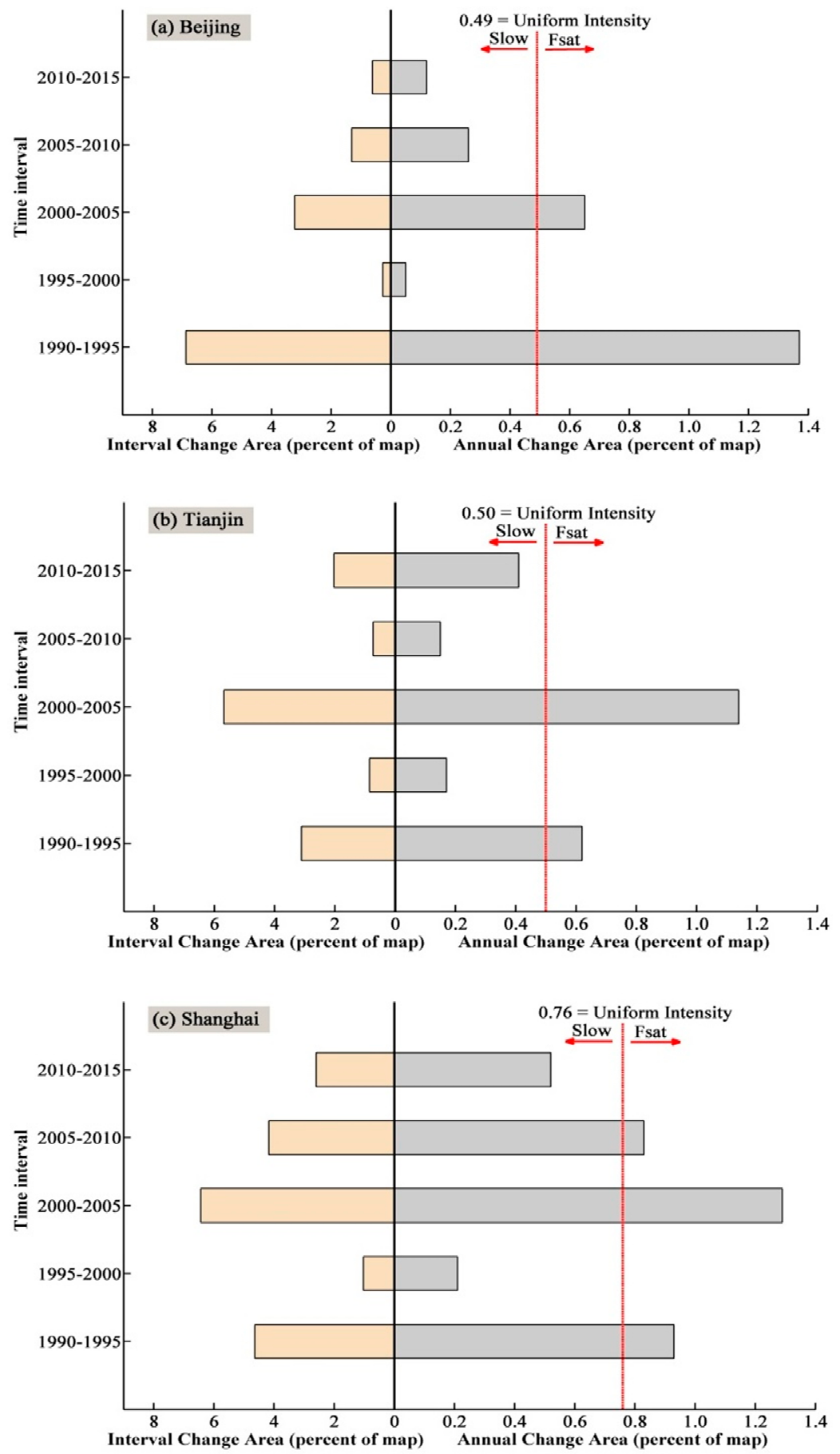

Figure 6. Cont. 


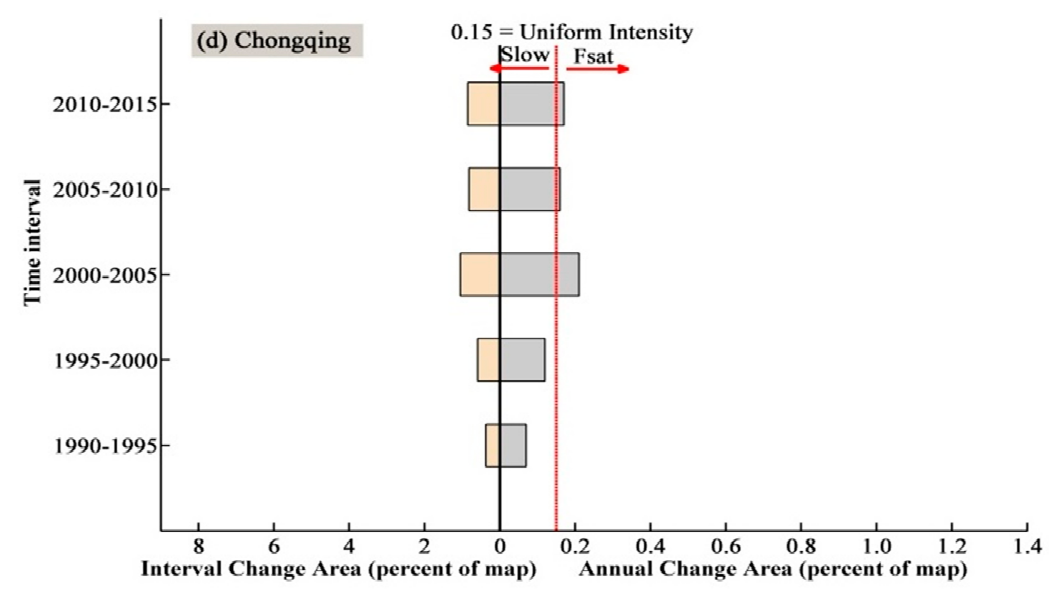

Figure 6. Time interval intensities of land use changes in (a) Beijing, (b) Tianjin, (c) Shanghai and (d) Chongqing during 1990-1995, 1995-2000, 2000-2005, 2005-2010, and 2010-2015. The bars that extend to the left of zero show the gross area of overall changes in each interval, while the bars that extend to the right of zero show intensity of annual area of change within each time interval. The dashed line was the uniform intensity. If the bar exceeds the uniform intensity line, the change in the land use in that time interval was relatively fast; otherwise, it was relatively slow.

The area and intensity of land use change in Beijing were the largest and fastest in 1990-1995, followed by 2000-2005, while the changes were the smallest and slowest in 1995-2000 (Figure 6a). The land use changes in Tianjin were relatively fast in 2000-2005 and 1990-1995 (Figure 6b). The rate of land use change in Shanghai was most rapid from 2000 to 2005, then 1990-1995 and 2005-2010, with the slowest in 1995-2000 (Figure 6c). Compared with Beijing, Tianjin, and Shanghai, the LUCC in Chongqing was slower during the study period. However, for this region, the bars on the right exceed the uniform intensity line from 2000 to 2015, which indicates that the rates of land use changes were relatively fast during this time (Figure $6 \mathrm{~d}$ ).

For the category intensity analysis of Beijing (Figure 7a), we found that the uniform intensity was the largest during 1990-1995 and approximately equal to 1.37\%; the gains of water and construction land were active, while the losses of arable and grassland were active, and the gain and loss of forest were both dormant.

The category intensity of land use change in Tianjin was largest in 2000-2005, at about $1.14 \%$, where the losses of forest, grassland, and water were active, while their gains were dormant. The gain intensity of construction land was greater than its loss and was active, while for the arable land, the intensity of loss was larger than the gain, but was not active at all (Figure $7 \mathrm{~b}$ ). In the interval 2000-2005, the uniform intensity of land use category change in Shanghai was $1.29 \%$, in which the gains of forest, grassland, and construction land were active, as were the losses of arable land and grassland. In 1990-1995, the losses of arable land and grassland and the gain in construction land were active, while the changes of forest and water were dormant. In addition to the active loss of grassland in 2005-2010 and the active gain of grassland in 2010-2015, the losses of arable and forest land and the gains in the extent of construction land were active over two intervals. In 1995-2000, the losses of arable and forest land and the gain of construction land were active in Shanghai (Figure 7c). The gain intensity of construction land in Chongqing was active in each time interval (Figure 7d). 


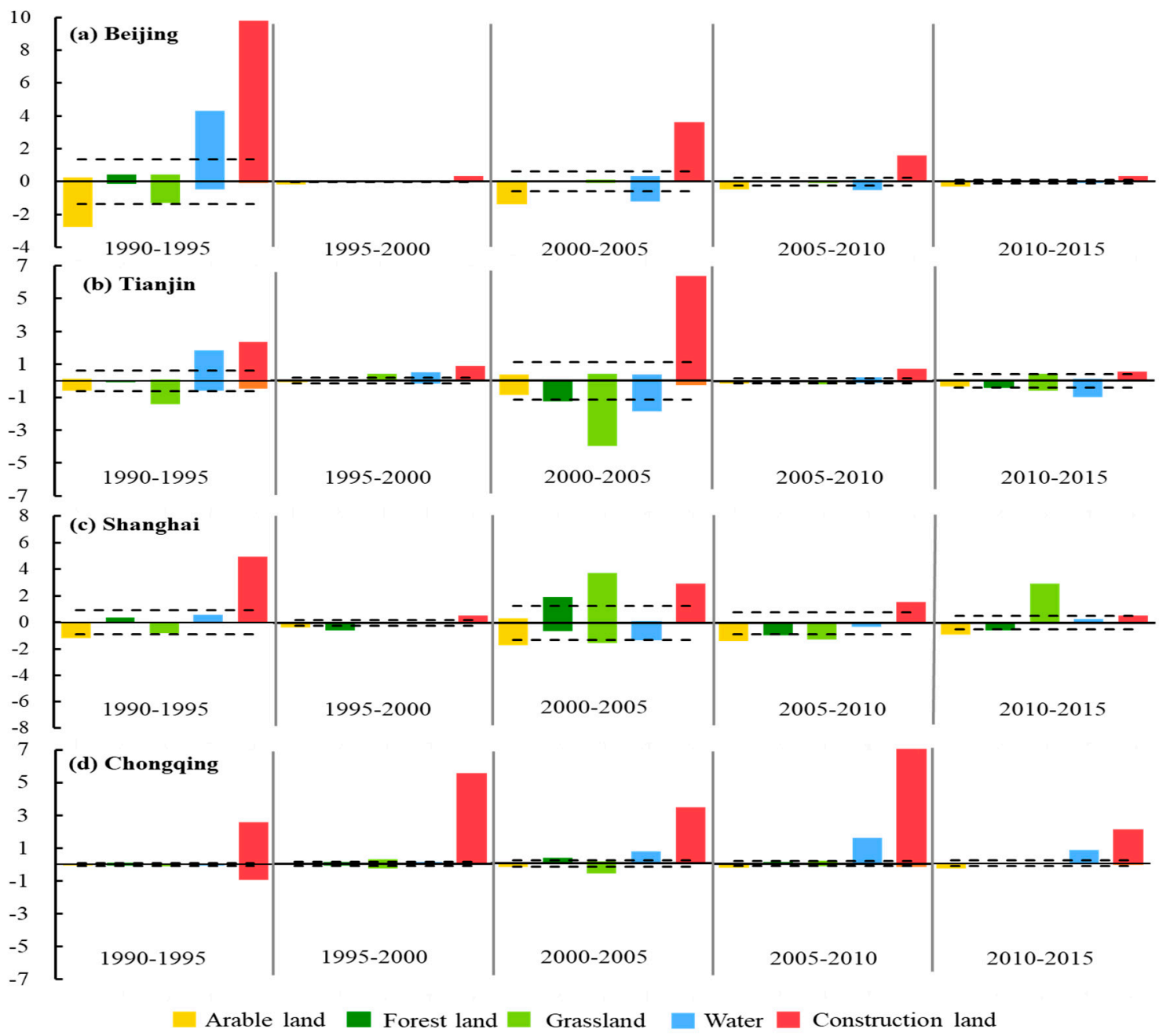

Figure 7. Category intensity analysis for the (a) Beijing, (b) Tianjin, (c) Shanghai and (d) Chongqing for 1990-1995, 1995-2000, 2000-2005, 2005-2010, and 2010-2015. The bars that are above the zero axis shows the intensity of gains, and those below the axis show losses. The dashed line is the uniform intensity. If the bar exceeds the line, it indicates that the change of a certain land use in that time interval was active; otherwise, the change was dormant.

From the interval intensity analysis and category intensity analysis, we found the rate of overall change of land use and the intensity of gain or loss of each land use type for the four study areas in each time interval. Then, we used the transition intensity analysis to determine the dominant conversion of land use change. These results are shown in Table 1. The arable land and grassland in Beijing were the types mainly reduced in each period and converted into construction land. While the increase of construction land mainly comes from arable land, the intensity of conversion from arable land into construction land was much greater than that of the conversion of grassland to construction land. In 1990-1995 and 2000-2005, the forest land was added to from arable land and grassland, and in the other three periods, it was mainly converted into grassland and construction land. For the land use changes in Tianjin, the arable, forest, and grassland types were mainly converted into construction land. Between 1990-1995 and 2000-2005, the forest land of Shanghai increased, mainly coming from arable land and grassland, with the arable land decreasing in extent and being converted into construction land. In Chongqing, the arable land was dominated by its conversion into construction land during each period. Forest land was added to by the conversion of grassland in 1990-1995, 2000-2005, and 2005-2010, and was reduced by its conversion into grassland or construction land in 1995-2000 and 2010-2015. The 
grassland mainly increased by the conversion of arable land in 2000-2005, and converted into forest land during the other periods.

Table 1. Conversion of dominant land uses during the five time intervals. "-"indicates the land use type converted into other types, while " + " indicates that the land use type was added to from other types, and "- indicates that the conversion was not active. $\mathrm{AL}=$ arable land, FL = forest land, $\mathrm{GL}=$ grassland, $\mathrm{CL}=$ construction land.

\begin{tabular}{|c|c|c|c|c|}
\hline Beijing & 1990-1995 & 1995-2000 & 2000-2005 & 2005-2010 \\
\hline $\mathrm{AL}$ &,$- \mathrm{CL}$ &,$- \mathrm{CL}$ &,$- \mathrm{CL}$ &,$- \mathrm{CL}$ \\
\hline FL & $+, \mathrm{AL}, \mathrm{GL}$ &,$- \mathrm{GL}$ & $+, \mathrm{AL}, \mathrm{GL}$ &,$- \mathrm{CL}$ \\
\hline GL &,$- \mathrm{CL}$ &,$- \mathrm{CL}$ &,$- \mathrm{CL}$ &,$- C L$ \\
\hline CL &,$+ \mathrm{AL}$ &,$+ \mathrm{AL}$ &,$+ \mathrm{AL}$ &,$+ \mathrm{AL}$ \\
\hline Tianjin & 1990-1995 & 1995-2000 & 2000-2005 & 2005-2010 \\
\hline $\mathrm{AL}$ &,$- \mathrm{CL}$ & $-, \mathrm{GL}, \mathrm{CL}$ &,$- C L$ &,$- C L$ \\
\hline FL &,$- \mathrm{CL}$ & - &,$- C L$ &,$- C L$ \\
\hline GL &,$- \mathrm{CL}$ & -,UL &,$- \mathrm{CL}$ &,$- \mathrm{CL}$ \\
\hline $\mathrm{CL}$ & $+, \mathrm{AL}, \mathrm{GL}$ & $+, \mathrm{AL}, \mathrm{FL}$ & $+, \mathrm{AL}, \mathrm{GL}$ & $+, \mathrm{AL}, \mathrm{GL}$ \\
\hline Shanghai & 1990-1995 & 1995-2000 & 2000-2005 & 2005-2010 \\
\hline $\mathrm{AL}$ &,$- \mathrm{CL}$ &,$- \mathrm{CL}$ &,$- \mathrm{CL}$ &,$- C L$ \\
\hline FL &,$+ \mathrm{AL}$ &,$- \mathrm{CL}$ & $+, \mathrm{AL}, \mathrm{GL}$ &,$- C L$ \\
\hline GL & - & - & - & - \\
\hline CL & $+, \mathrm{AL}, \mathrm{GL}$ & $+, \mathrm{AL}, \mathrm{FL}$ & $+, \mathrm{AL}, \mathrm{FL}$ &,$+ \mathrm{AL}$ \\
\hline Chongqing & 1990-1995 & 1995-2000 & 2000-2005 & 2005-2010 \\
\hline $\mathrm{AL}$ &,$- \mathrm{CL}$ &,- CL & $-C L$ &,$- C L$ \\
\hline FL &,$+ \mathrm{GL}$ & $-, \mathrm{GL}, \mathrm{CL}$ &,$+ \mathrm{GL}$ &,$+ \mathrm{GL}$ \\
\hline GL & -,FL & -,FL,CL &,$+ \mathrm{AL}$ & -,FL,CL \\
\hline CL &,$+ \mathrm{AL}$ &,$+ \mathrm{AL}$ &,$+ \mathrm{AL}$ &,$+ \mathrm{AL}$ \\
\hline
\end{tabular}

\section{Discussion}

\subsection{The Impact of Socio-Economic Development on Land Use Change}

Land use change is the result of both natural and human activities [14]. However, over time scales of several decades or even hundreds of years, the impact of natural factors is mainly embodied in cumulative and background effects, while the impact of human factors as the main cause of land use change is relatively active and easy to detect $[53,54]$. Among the many factors of human activities, socio-economic development and population growth are particularly important for the structure of land use change. This leads to changes differing between regions according to the degree of socio-economic development and population growth.

Figure 8 shows the GDP and population change of the four municipalities, all of which have grown significantly in the period between 1990 and 2015. Among them, Shanghai has the highest rate of GDP and population growth, $978.06 \times 10^{8}$ yuan/y and $50.90 \times 10^{4}$ persons/y, respectively. The change rates of GDP and population for each of the study intervals (1990-1995, 1995-2000, 2000-2005, 2005-2010, and $2010-2015$ ) were $219.76 \%, 90.89 \%, 93.83 \%, 85.63 \%$, and $46.36 \%$ and $6 \%, 13.76 \%, 17.51 \%, 21.82 \%$, and $4.89 \%$, respectively. We observe from Figure 6 that the land use change intensity in Shanghai was the highest in 2000-2005, which corresponds to when the rates of economic and population growth were the largest. During different study periods in Beijing and Tianjin, the intensity of land use change was also active during times of high economic and population growth rates, where the GDP and population change rates in Beijing were $880.52 \times 10^{8}$ yuan/y and $47.18 \times 10^{4}$ persons/y, respectively, and $628.63 \times 10^{8}$ yuan/y and $24.77 \times 10^{4}$ persons/y, respectively, in Tianjin. Chongqing's GDP was the lowest and its population the largest, while its GDP and population growth were also the slowest of the four study areas, leading to the lowest land use change intensity $(0.15 \%)$. LUCC here was active in 
2000-2005, during which the rate of GDP and population growth in Chongqing were the largest of the examined study periods at $128.55 \%$ and $4.24 \%$, respectively, but they were lower than the change rates of the other regions during the same period.

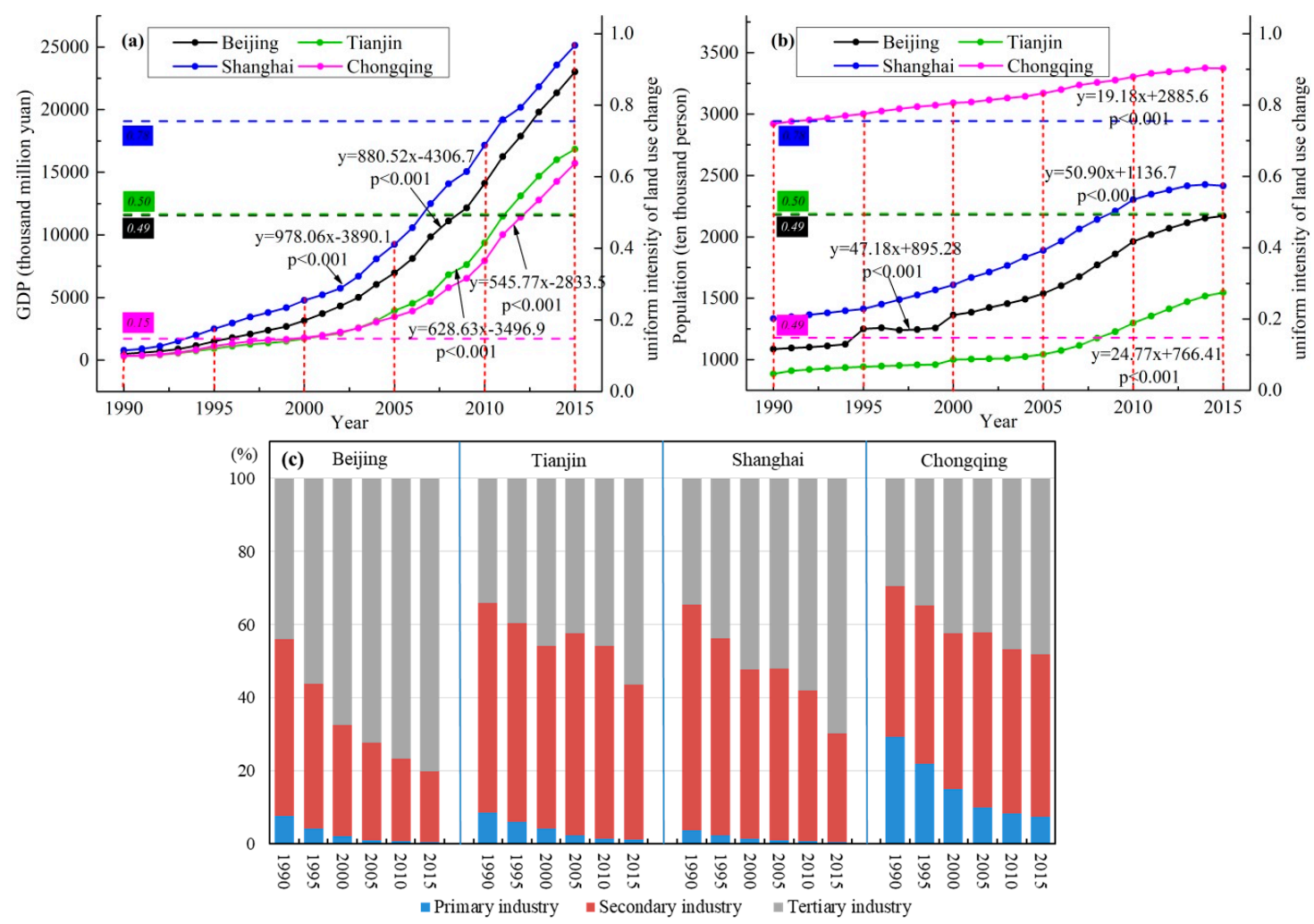

Figure 8. Changes in the (a) GDP, (b) population and (c) three industries during 1990-2015 for the four municipalities.

In addition, we can see from Figure $8 c$ that the proportion of primary industry was reduced and that secondary and tertiary industries increased, with the proportion made up of tertiary industry in Beijing and Shanghai being larger than for secondary industries. These changes in industrial structure will inevitably lead to a sharp increase in the population, the expansion of the port (for the case of Shanghai), the establishment of a large number of industrial plants, and an increase in infrastructure. This will lead to the decrease in available arable and forest land, and an increase in industrial and residential land.

In general, the rates of GDP and population growth in Shanghai were the fastest of the four municipalities, while the intensity of land use changes was the largest $(0.76 \%)$. By contrast, the rates of GDP and population growth in Chongqing were the slowest, while the intensity of LUCC was the smallest, indicating that where there was more economic and population growth, the intensity of land use change was greater in Chongqing.

\subsection{The Impact of Government Policy on Land Use Change}

A series of policies implanted by the state have had an important impact on land use change. From the intensity analysis, we found that the rate of land use change was relatively high in 1990-1995, but in 1995-2000, the intensity changes suddenly decreased, which was also found in the research of Liu et al. [55]. The cause of this phenomenon is that the 1990s were an important period in China's overall transition from planned to market economy. In the first five years of the 1990s, the all-around development of the social economy laid a certain material foundation for the development of urbanization, and promoted the development of China's real estate industry. This formed a strong 
momentum behind "development zone fever" and "real estate fever", leading to a large loss of cultivated land and the rapid expansion of rural residential areas. Since then, land management policies and regulations have been promulgated to effectively contain the rapid change of land use, such as the "Regulations on the Protection of Basic Farmland", "Dynamic Equilibrium of Total Cultivated Land", and "Balance of Cultivated Land Occupation and Compensation" in 1994, 1996, and 1998, respectively (Figure 9). Since 2000, with China's accession to the World Trade Organization, the country has entered a stage of rapid industrialization and urbanization, which has driven the rapid expansion of urban land. In 2010, China issued the planning of principal functional zoning regulations, dividing the land space into key development zones, protected development zones, restricted development zones, and prohibited development zones [56]. Under the policy control of the main functional areas, the urban construction land intensity of Beijing, Shanghai, and Tianjin in 2010-2015 was lower than that during the previous 10 years [57].

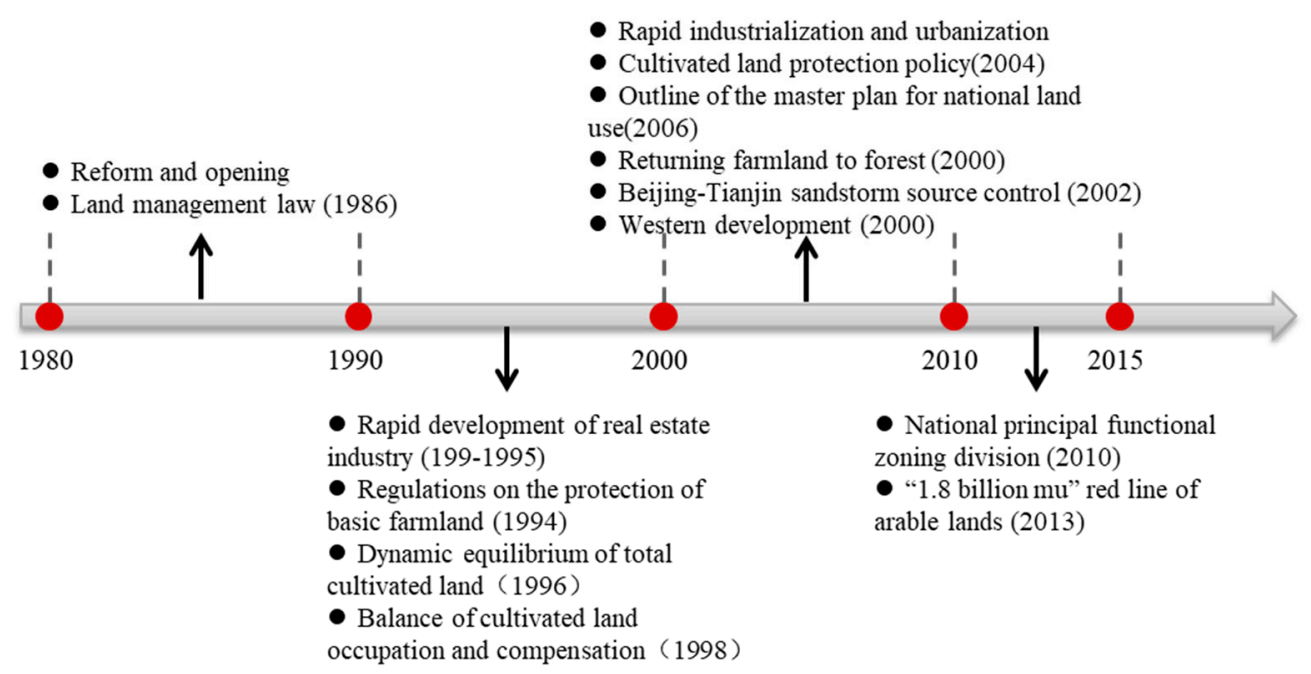

Figure 9. The impact of national policies and urban plans on land use change.

Since the start of the 21st century, China has implemented a series of regional development strategies, such as the "western development", "the revitalization of old industrial bases in the northeast", and the "rise of the central region", which have promoted the rapid development of the social economy and have had an important impact on the dynamics of LUCC [48]. Beijing and Tianjin have carried out a series of projects, such as the "Three North" shelter forest development, ecological agriculture development, the conversion of farmland to forests, the "Beijing Tianjin sandstorm source control", and greening around the capital and Taihang Mountain. These have produced obvious effects on regional land use change, especially in Beijing during 2010-2013, with the area of garden and forest land showing a growth trend. Since the reform and the opening up of the economy, in order to promote economic development, Shanghai began to expropriate and rent land in the suburbs in the 1980s. Over the past 20 years, a total of $9.6 \times 10^{4} \mathrm{~km}^{2}$ of land has been expropriated, mainly for land acquisition, and most of which was used for non-productive purposes, such as municipal and real estate projects and the construction of public facilities. Thus, the urban land use pattern has significantly changed.

Since 1997, the year Chongqing became a municipality, the government has promulgated laws and regulations on farmland protection and land use, which reduced the rate of cultivated land to a certain extent. Furthermore, the western development, the Three Gorges project, and the policy of returning farmlands to forests have resulted in changing land use patterns in Chongqing. In addition, the overall planning of the government and the functional orientation of each district and county have also had a profound impact on urban land use change [44-47]. 


\subsection{The Impact of Major Urban Events on Land Use Change}

The impact of major urban events on land use type distribution was mainly caused by the change in the urban spatial and economic scales. Moreover, significant events play a more important role in the spatial expansion of long time series. The 2008 Beijing Olympic Games and the 2010 Shanghai World Expo are the main reasons for the change of land use patterns around the meeting sites [58,59], and caused land use changes in the two regions to be relatively high in the period 2000-2005. Figure 10 shows the differences arising before starting construction and after the completion of major events, which, in Beijing, covered the surroundings of the national aquatics center and national stadium, and, in Shanghai, the Expo Park, exhibition hall, Expo Axis, etc. It can easily be seen from this figure that, as a result of these events, significant changes had taken place in the urban landscapes of these municipalities. In addition to these large-scale activities, with the rapid development of the economy, the launch of various construction projects also affected the land use changes around these construction projects.
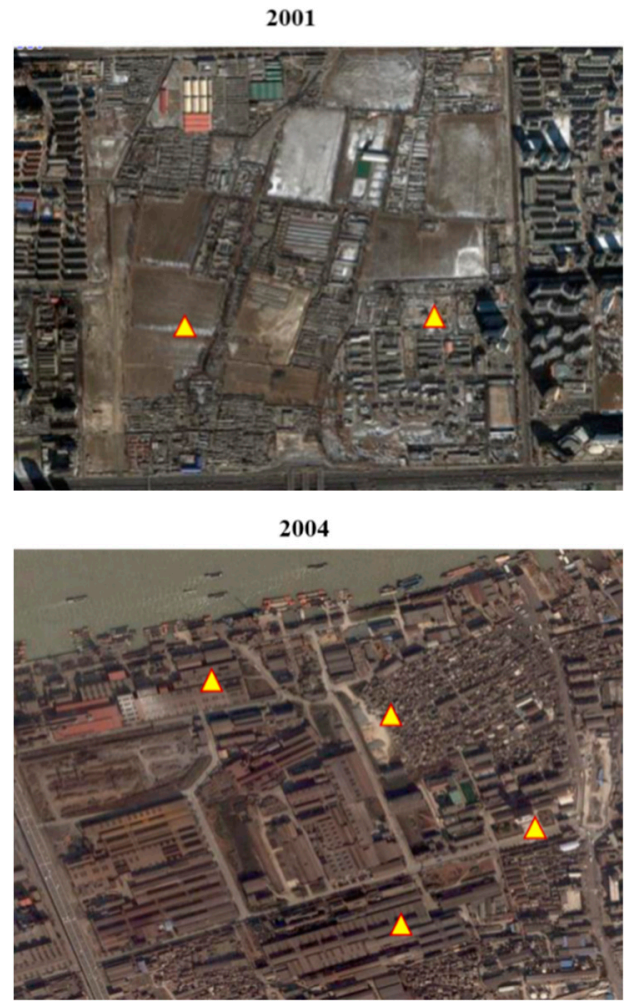

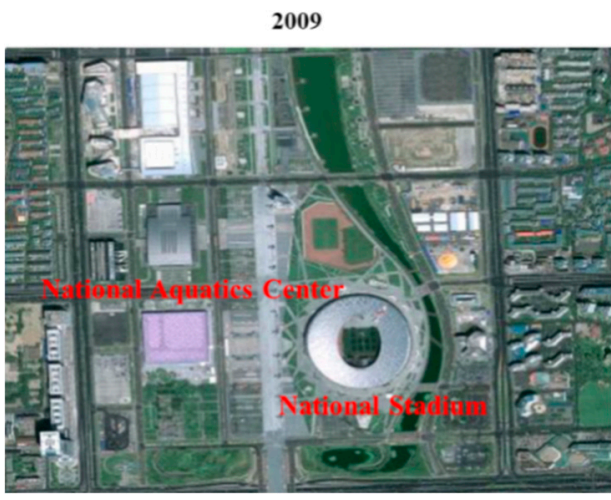

2011

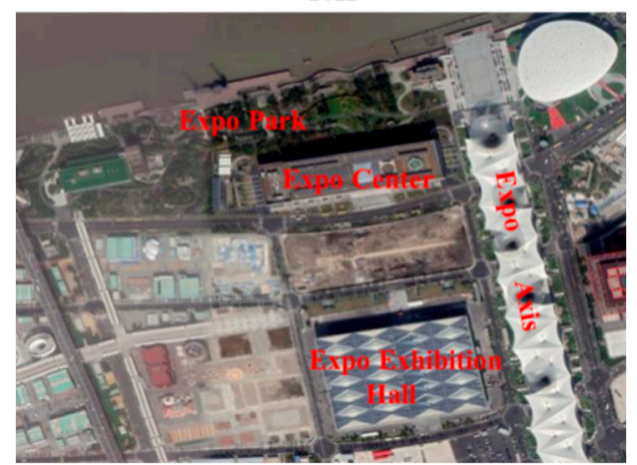

Figure 10. Image showing the differences in Beijing (above) and Shanghai (below) before and after the Olympic Games and World Expo, respectively. The triangles in the older photos indicate the features that were there prior to the construction of the labeled elements in the more recent photos.

\section{Conclusions}

In this study, the spatiotemporal variations of land use change in Beijing, Tianjin, Shanghai, and Chongqing were analyzed based on five time segments of land use classification data from 1990 to 2015. This was done by intensity analysis and a barycenter migration model. This allowed a qualitative study of the driving forces behind such changes. The results indicated that the land use change intensity in Shanghai was the most rapid, followed by Beijing and Tianjin, with Chongqing being the slowest. The decrease in arable land and the increase in construction land were both active in each time period in all four municipalities; the arable land was mainly transformed into construction land. Correspondingly, the moving distances of the barycenter of construction land were longer than those of arable land. The intensity of land use change was affected by economic development, population growth, policy, etc.; 
where there was a high rate of economic and population growth, the intensity of land use change was large.

In this paper, the dynamic changes of land use in the four municipalities were analyzed based on intensity analysis for three levels: Interval level, category level, and transition level. This calculates the contribution of each category to the total change, the loss and gain of different categories, and their intensities for each period. It also determines the extent of the conversion and intensity between each category, providing more detailed information for the study of land use change. A great deal of previous research found that this method was superior to the widely used dynamic degree model and the Markov model $[40,60]$. However, the intensity analysis also has shortcomings and must be improved. For example, this method does not consider data uncertainty, the influences of the overlap between different categories, or their spatial distributions. Therefore, spatial variation analysis remains inadequate. To solve these problems, the intensity analysis framework must be improved by adding information about the spatial distribution of the various categories of land use into the analytical process so that the characteristics of both the spatial and temporal variations can be analyzed.

In addition, land use change is affected by many factors, as it occurs under the background of global climate change and the acceleration of urbanization. Hence, the integration of high-resolution remote sensing data and natural and socio-economic data should be strengthened in future research, so as to analyze the driving forces and comprehensively identify the mechanisms of land use change, while, in turn, applying these results to forecasting and the regulation of future trends of land use.

Author Contributions: All authors contributed significantly to this manuscript. Y.B. (Yuhai Bao) was responsible for the original idea and the theoretical aspects of the paper. G.B. and X.H. were responsible for the data collection and preprocessing, A.R. and Y.B. (Yongbin Bao) were responsible for the methodology design, and S.T. drafted the manuscript; all authors read and revised the final manuscript. All authors have read and agreed to the published version of the manuscript.

Funding: This study was supported by the Special Fund for Science and Technology for Research Investigation (No. 2017FY101301-4), the Key Program of National Natural Science Foundation of China (No. 61631011), and the Research Foundation for Advanced Talents of Inner Mongolia Normal University (2018YJRC007, 2019YJRC002).

Acknowledgments: We would like to thank the Data Center for Resources and Environmental Sciences, Chinese Academy of Sciences (RESDS, http://www.resdc.cn) for providing the land use data set.

Conflicts of Interest: The authors declare no conflict of interest.

\section{References}

1. Mooney, H.A.; Duraiappah, A.; Larigauderie, A. Evolution of natural and social science interactions in global change research programs. Proc. Natl. Acad. Sci. USA 2013, 110, 3665-3672. [CrossRef] [PubMed]

2. Sterling, S.M.; Ducharne, A.; Polcher, J. The impact of global land-cover change on the terrestrial water cycle. Nat. Clim. Chang. 2012, 3, 385-390. [CrossRef]

3. Tian, H.Q.; Chen, G.; Zhang, C. Century-scale response of ecosystem carbon storage to multifactorial global change in the Southern United States. Ecosystems 2012, 15, 674-694. [CrossRef]

4. Meyfroidt, P.; Lambin, E.F.; Erb, K. Globalization of land use: Distant drivers of land change and geographic displacement of land use. Curr. Opin. Environ. Sustain. 2013, 5, 1-7. [CrossRef]

5. Liu, X.L.; Fang, C.L. Research progress and prospects of urban agglomeration resource environmental bearing capacity. Prog. Geogr. 2008, 27, 35-42.

6. Gauquelin, T.; Michon, G.; Joffre, R.; Duponnois, R.; Génin, D.; Fady, B.; Dagher-Kharrat, M.B.; Derridj, A.; Slimani, S.; Badri, W.; et al. Mediterranean forests, land use and climate change: A social-ecological perspective. Reg. Environ. Chang. 2018, 18, 623-636. [CrossRef]

7. Kumpula, T.; Pajunen, A.; Kaarlejärvi, E.; Forbes, B.C.; Stammler, F. Land use and land cover change in arctic Russia: Ecological and social implications of industrial development. Glob. Environ. Chang. 2011, 21, 550-562. [CrossRef]

8. Hualin, X.; Peng, W.; Hongsheng, H. Ecological risk assessment of land use change in the Poyang lake eco-economic zone, China. Int. J. Environ. Res. Public Health 2013, 10, 328-346. 
9. Turner, B.L.; Skole, D.; Sanderson, S.; Fischer, G.; Fresco, L.; Leemans, R. Land-Use and Land-Cover Change; Science/Research Plan; IGBP Report No. 35 and HDP Report No. 7; IGBP: Stochkholm, Sweden, 1995.

10. Li, X.B. A review of the international researches on land use/land cover change. Aata Geogr. Sin. 1996, 51, 553-558.

11. Liu, J.Y.; Wang, S.Q.; Chen, J.M.; Liu, M.L.; Zhuang, D.F. Storages of soil organic carbon and nitrogen and land use changes in China: 1990-2000. Aata Geogr. Sin. 2004, 59, 483-496.

12. Overmars, K.P.; Verburg, P.H. Analysis of land use drivers at watershed and household level linking two paradigms at the Philippine forest fringe. Int. J. Geogr. Inf. Sci. 2005, 19, 125-152. [CrossRef]

13. Veldkamp, A.; Lambin, E.F. Editorial predicting land-use change. Agric. Ecosyst. Environ. 2001, 85, 379-386. [CrossRef]

14. Veldkamp, A.; Fresco, L.O. Reconstructing land use drivers and their spatial scale dependence for Costa Rica (1973 and 1984). Agric. Syst. 1997, 55, 19-43. [CrossRef]

15. Yu, X.X.; Yang, G.S. The advances and problems of land use and land cover change research in China. Prog. Geogr. 2002, 21, 51-57.

16. Islam, M.R.; Miah, M.G.; Inoue, Y. Analysis of land use and land cover changes in the coastal area of Bangladesh using Landsat imagery. Land Degrad. Dev. 2016, 27, 899-909. [CrossRef]

17. Pontius, R.G.; Shusas, E.; Mceachern, M. Detecting important categorical land changes while accounting for persistence. Agric. Ecosyst. Environ. 2004, 101, 251-268. [CrossRef]

18. Wang, G.; Liu, Y.; Li, Y.; Chen, Y. Dynamic trends and driving forces of land use intensification of cultivated land in China. J. Geogr. Sci. 2015, 25, 45-57. [CrossRef]

19. Wang, J.; Chen, Y.; Shao, X.; Zhang, Y.; Cao, Y. Land-use changes and policy dimension driving forces in China: Present, trend and future. Land Use Policy 2012, 29, 737-749. [CrossRef]

20. Mas, J.F.; Kolb, M.; Paegelow, M.; Olmedo, M.T.C.; Houet, T. Inductive pattern-based land use/cover change models: A comparison of four software packages. Environ. Model. Softw. 2014, 51, 94-111. [CrossRef]

21. Liu, T.; Yang, X. Monitoring land changes in an urban area using satellite imagery, GIS and landscape metrics. Appl. Geogr. 2015, 56, 42-54. [CrossRef]

22. Abuelaish, B.; Olmedo, M.T. Scenario of land use and land cover change in the Gaza Strip using remote sensing and GIS models. Arab. J. Geosci. 2016, 9, 1-14. [CrossRef]

23. Zhou, L.F.; Li, C.M.; Chen, Q.X.; Zhang, Y.L. Forecasting analysis of land use dynamic change in Liaohe River Delta wetlands. Adv. Mater. Res. 2013, 726-731, 3313-3319. [CrossRef]

24. Burgi, M.; Anna, M.H.; Nina, S. Driving forces of landscape change-current and new directions. Landsc. Ecol. 2004, 19, 857-868. [CrossRef]

25. Takada, T.; Miyamoto, A.; Hasegawa, S.F. Derivation of a yearly transition probability matrix for land-use dynamics and its applications. Landsc. Ecol. 2010, 25, 561-572. [CrossRef]

26. Liu, R.; Zhu, D. Methods for detecting land use changes based on the land use transition matrix. Resour. Sci. 2010, 32, 1544-1550.

27. Tian, X.; Wang, X.; Kadipov, K.G.; Jia, H. Land use/cover dynamic change and landscape pattern analysis in Kayrakkum reservoir area during past 40 years. Trans. Chin. Soc. Agric. Eng. 2014, 30, 232-241.

28. Hu, Y.; Zhen, L.; Zhuang, D. Assessment of land-use and land-cover change in Guangxi, China. Sci. Rep. 2019, 9, 2189. [CrossRef]

29. Wu, X.; Shen, Z.; Liu, R.; Ding, X. Land use/cover dynamics in response to changes in environmental and socio-political forces in the upper reaches of Yangtze river, China. Sensors 2008, 8, 8104-8122. [CrossRef]

30. Wang, X.; Bao, Y. Study on the methods of land use dynamic change research. Prog. Geogr. 1999, $18,81-87$.

31. Zhang, L.; Yang, G.F.; Liu, J.P. The dynamic changes and hot spots of land use in Fushun city from 1986 to 2012. Sci. Geogr. Sin. 2014, 34, 185-191.

32. Chou, Q.C.; Li, R.L.; Xu, H.; Liu, J.; Shi, X. Study on the land use/cover changes of mangrove reserve of Shenzhen Bay based on remote sensing date. Adv. Mater. Res. 2014, 962-965, 2533-2540. [CrossRef]

33. Fang, G.; Yang, J.; Su, H.M. Dynamic analysis of land use/cover change in Dangshan County. Adv. Mater. Res. 2012, 356-360, 2874-2879. [CrossRef]

34. Pontius, R.G.; Huang, J.; Jiang, W.; Khallaghi, S.; Lin, Y.; Liu, J.; Quan, B.; Ye, S. Rules to write mathematics to clarify metrics such as the land use dynamic degrees. Landsc. Ecol. 2017, 32, 2249-2260. [CrossRef]

35. Aldwaik, S.Z.; Pontius, R.G., Jr. Intensity analysis to unify measurements of size and stationarity of land changes by interval, category, and transition. Landsc. Urban Plan 2012, 106, 103-114. [CrossRef] 
36. Huang, J.; Pontius, R.G., Jr.; Li, Q.; Zhang, Y. Use of intensity analysis to link patterns with processes of land change from 1986 to 2007 in a coastal watershed of southeast China. Appl. Geogr. 2012, 34, 371-384. [CrossRef]

37. Mallinis, G.; Koutsias, N.; Arianoutsou, M. Monitoring land use/land cover transformations from 1945 to 2007 in two peri-urban mountainous areas of Athens metropolitan area, Greece. Sci. Total Environ. 2014, 490, 262-278. [CrossRef]

38. Zhou, P.; Huang, J.L.; Pontius, R.G., Jr.; Hong, H. Land classification and change intensity analysis in a coastal watershed of southeast China. Sensors 2014, 14, 11640-11658. [CrossRef]

39. Sun, Y.; Guo, T.; Cui, X. Intensity analysis and stationarity of land use change in Kunming City. Prog. Geogr. 2016, 35, 245-254.

40. Huang, B.; Huang, J.; Pontius, R.G., Jr.; Tu, Z. Comparison of Intensity Analysis and the land-use dynamic degrees to measure land changes outside versus inside the coastal zone of Longhai. China Ecol. Indic. 2018, 89, 336-347. [CrossRef]

41. Shi, P.J.; Jiang, Y.; Wang, J.A. Land Use/Cover Change and Ecosystem Security. Sci. Total Environ. 2004. [CrossRef]

42. Zhang, C.; Tian, H.; Pan, S.; Liu, M.; Lockaby, G.; Schilling, E.B. Effects of forest regrowth and urbanization on ecosystem carbon storage in a rural-urban gradient in the southeastern United States. Ecosystems 2008, 11, 1211-1222. [CrossRef]

43. Reid, R.S.; Kruska, R.L.; Muthui, N.; Taye, A.; Wotton, S.; Wilson, C.J. Land-use and land-cover dynamics in response to changes in climatic, biological and socio-political forces: The case of southwestern Ethiopia. Landsc. Ecol. 2000, 15, 339-355. [CrossRef]

44. Xu, W.; Chen, M. Land use change and driving force in Beijing based on Landsat images. Beijing Surv. Mapp. 2018, 32, 58-61.

45. Wang, R.; Murayama, Y. Change of land use/cover in Tianjin city based on the Markov and cellular automata models. ISPRS Int. J. Geo-Inf. 2017, 6, 150. [CrossRef]

46. Shi, L.J.; Wang, S.Y.; Yao, X.J.; Niu, J.J.; Yu, L.Z. Spatial and temporal variation characteristics of land use and driving force in Shanghai city from 1994 to 2006. Resour. Environ. Yangtze Basin 2012, 21, 1468-1479.

47. Zhang, Y.Y.; Li, Z.F. Principal Component analysis on land use change and its driving forces since Chongqing become a municipality. J. Anhui Agric. Sci. 2012, 40, 1197-1199, 1202.

48. Liu, J.Y.; Kuang, W.H.; Zhang, Z.X. Spatiotemporal characteristics, patterns and causes of land use changes in China since the late 1980s. Acta Geogr. Sin. 2014, 69, 3-14. [CrossRef]

49. Liu, J.Y.; Zhang, Z.X.; Xu, X.L.; Kuang, W.H.; Zhou, W.C.; Zhang, S.W.; Li, R.; Yan, C.; Yu, D.; Wu, S.; et al. Spatial patterns and driving forces of land use change in China during the early 21st century. J. Geogr. Sci. 2010, 20, 483-494. [CrossRef]

50. Zhang, F.; Tiyip, T.; Feng, Z.D.; Kung, H.T.; Johnson, V.C.; Ding, J.L. Spatio-temporal patterns of land use/cover changes over the past 20 years in the middle reaches of the Tarim River, Xinjiang, China. Land Degrad. Dev. 2015, 26, 284-299. [CrossRef]

51. Wang, G.Q.; Wang, S.Y.; Chen, Z.X. Land-use/land-cover changes in the Yellow River basin. J. Tsinghua Univ. (Sci. Technol.) 2004, 44, 1218-1222.

52. Lian, X.M. Analysis on the space evolvement track of population gravity center, employment gravity center and economic gravity center. Popul. J. 2007, 3, 23-28.

53. Xu, G.C.; Kang, M.Y.; Li, Y.F. Analysis of land use change and its driving forces in Xiling'ol League. Resour. Sci. 2011, 33, 690-697.

54. Xie, F.; Shu, X.B.; Liao, F.Q. Analysis on land use changes and driving forces in Fuliang County, Jiangxi Province. Res. Soil Water Conserv. 2011, 18, 213-221.

55. Liu, J.Y.; Zhang, Z.X.; Zhuang, D.F.; Wang, Y.M.; Zhou, W.C.; Zhang, S.W.; Li, R.D.; Jiang, N.; Wu, S.X. A study on the spatial-temporal dynamic changes of land-use and driving forces analyses of China in the 1990s. Geogr. Res. 2003, 22, 1-12.

56. Fan, J. Draft of major function oriented zoning of China. Acta Geogr. Sin. 2015, 70, 186-201.

57. Kuang, W.H.; Liu, J.Y.; Dong, J.W.; Chi, W.; Zhang, C. The rapid and massive urban and industrial land expansions in China between 1990 and 2010: A CLUD-based analysis of their trajectories, patterns, and drivers. Landsc. Urban Plan. 2016, 145, 21-33. [CrossRef] 
58. Ni, Y. Impact Effect and Mechanism of Urban Mega-Event on Land Use-A Case of Shanghai World Expo. Master's Thesis, Zhejiang University, Hangzhou, China, 2013.

59. Kuang, W.H.; Liu, J.Y.; Shao, Q.Q.; Sun, C.Y. Spatio-temporal patterns and driving forces of urban expansion in Beijing central city since 1932. J. Geo-Inf. Sci. 2009, 11, 428-435. [CrossRef]

60. Pelorosso, R.; Chiesa, S.D.; Tappeiner, U.; Leone, A.; Rocchini, D. Stability analysis for defining management strategies in abandoned mountain landscapes of the Mediterranean basin. Landsc. Urban Plan. 2011, 103, 335-346. [CrossRef]

(C) 2020 by the authors. Licensee MDPI, Basel, Switzerland. This article is an open access article distributed under the terms and conditions of the Creative Commons Attribution (CC BY) license (http://creativecommons.org/licenses/by/4.0/). 